\title{
Visible Parts, Invisible Whole: Swedish Technology Student Teachers' Conceptions about Technological Systems
}

\author{
Jonas Hallström and Claes Klasander
}

\section{Linköping University Post Print}

\section{Tweet}

N.B.: When citing this work, cite the original article.

The original publication is available at www.springerlink.com:

Jonas Hallström and Claes Klasander, Visible Parts, Invisible Whole: Swedish Technology Student Teachers' Conceptions about Technological Systems, 2016, International journal of technology and design education, 1-19.

http://dx.doi.org/10.1007/s10798-016-9356-1

Copyright: Springer Verlag (Germany)

http://www.springerlink.com/?MUD=MP

Postprint available at: Linköping University Electronic Press

http://urn.kb.se/resolve?urn=urn:nbn:se:liu:diva-124395 
2016-01-10

\title{
Visible Parts, Invisible Whole: Swedish Technology Student Teachers' Conceptions about Technological Systems
}

\author{
Jonas Hallström* and Claes Klasander \\ Technology and Science Education Research (TESER), Dept. of Social and Welfare Studies, Linköping \\ University, S-601 74 Norrköping, Sweden. \\ *E-mail: jonas.hallstrom@liu.se
}

Technological systems are included as a component of national technology curricula and standards for primary and secondary education as well as corresponding teacher education around the world. Little is known, however, of how pupils, students, and teachers conceive of technological systems. In this article we report on a study investigating Swedish technology student teachers' conceptions of technological systems. The following research question is posed: How do Swedish technology student teachers conceive of technological systems? Data was collected through in-depth qualitative surveys with 26 Swedish technology student teachers. The data was analysed using a hermeneutic method, aided by a theoretical synthesis of established system theories (system significants). The main results of the study are that the technology student teachers expressed diverse conceptions of technological systems, but that on average almost half of them provided answers that were considered as undefined. The parts of the systems that the students understood were mostly the visible parts, either components, devices, or products such as buttons, power lines, hydroelectric plants, or the interface with the software inside a mobile phone. However, the 'invisible' or abstract aspects of the technological systems, such as flows of information, energy or matter, or control operations were difficult to understand for the majority of the students. The flow of information was particularly challenging in this regard. The students could identify the input and often the output of the systems, that is, what systems or components $d o$, but the processes that take place within the systems were elusive. Comparing between technological systems also proved difficult for many students. The role of humans was considered important but it was mostly humans as users not as actors on a more systemic level, for example, as system owners, innovators, or politicians. This study confirms previous research in that the students had a basic understanding of structure, input and output of a technological system. Thus, the adult students in this study did not seem to have better understanding of technological systems than school pupils and teachers in previous studies, although this is in line with previous investigations on the general system thinking capabilities of children and adults. The most important implication of this study is that students need to be trained in systems thinking, particularly regarding how components work and connect to each other, flows (especially of information), system dependency, and the human role in technological systems.

Keywords: technological systems, conceptions, technology teacher education, systems theory, Sweden

\section{Introduction}

Technology has become increasingly systemic in the last 150 years as the interconnected elements of technological systems have become vital to a multitude of human activities (Hughes 2004; Hamlin 1992). Technological systems are therefore part of our everyday lives; we use them, affect them and are affected by them. They are interwoven into our society to such an extent that we often take them for granted and they almost become invisible to us, especially since much of the infrastructure is either in the ground beneath us or takes more invisible forms such as the air waves. Research into the history and sociology of technology in the last few decades has also shown that technological systems have partially different characteristics and dynamics compared to single objects and artefacts (Hughes 1983, 1987; Ingelstam 2002). A technological system constitutes a whole that is more than the sum of 
all its individual parts; it consists of components and connections between them, but serves a function that is not immediately reducible to each component. Consequently, in order for students to understand technology in all its variety they also have to be introduced to technological systems and their characteristics (Rossouw, Hacker, and De Vries 2011). Several countries have also adopted an explicit technological system component in their technology curricula, the United States and New Zealand being the most prominent examples (Standards for Technological Literacy 2000; Technology in the New Zealand Curriculum 2007).

The Swedish technology curriculum for compulsory school (ages 7-16) has included a system component for 35 years. The first mandatory national technology curriculum in 1980 contained certain system-related content, for instance, computers and communications systems (Läroplan för grundskolan, Lgr 80 1980). Focussing on broad technological literacy, the curricular rubric Components and systems in the 1994 national curriculum for the first time provided more consistent subject content concerning systems. The current national curriculum of 2011 does not have such an explicit focus on technological systems. Instead, systems are now a part of the rubric Technology, humans, society and environment. Nevertheless, it is the first time in a Swedish curriculum that a core content in technology has been worked out, and the study of technological systems is prescribed content for students aged 10-16 years (Swedish Technology Curriculum, Lpo 94 2000; Läroplan för grundskolan, förskoleklassen och fritidshemmet 2011).

However, there have been no Swedish studies of technological systems in relation to teacher education for the compulsory school. It is crucial to bring technology student teachers into our understanding of technology in the school, since teachers acquire much of their subject knowledge during their teacher education (Mc Glashan and Wells 2013; Koski and de Vries 2013). In this article, therefore, we report on a study of how Swedish technology student teachers conceive of technological systems. The following research question is posed: How do Swedish technology student teachers conceive of technological systems?

\section{Pupils' and Teachers' Conceptions of Technological Systems}

Recent international research in technology education has investigated systemic issues and perspectives (Compton and France 2007; Frank 2006; Jones 2003; Williams 2000; Zuga 1994, 2004). Arguments have been made that ' $[\mathrm{t}] \mathrm{he}$ understanding of systems is essential in developing knowledge in technology' (Jones 2003, 90). Yet few studies have been made regarding how pupils, adult students and teachers understand technological systems. Mioduser et al. (1996) investigated the mental models that American middle-school pupils produce of control systems such as automatic doors, heating/cooling systems, and various household devices, before, during and after instruction.

Furthermore, they studied the pupils' 'conceptions, missing conceptions, and misconceptions' of these control systems on three main levels: device knowledge, perception of the control process, and conception of the flow of information in the system. Their conclusions were that the pupils' understanding prior to instruction was very poor (but a little better after). Their device knowledge, for example, was poor, which means that they lacked an accurate understanding of common components and how these affect the system. Control features of the system were similarly poorly understood as well as the flow of information in the system, while system structure was well understood (Mioduser, Venezky, and Gong 1996).

Ginns et al. (2005) carried out an intervention on technological systems in an Australian grade six class, and concluded that an 'improvement was observed in students' abilities to describe relationships between inputs, processes and outputs [. . .]' (Ginns, Norton, and McRobbie 2005, 47). Koski and de Vries (2013) designed an intervention study in which primary pupils and teachers did a pre-test, the teachers thereafter taught lessons and then the pupils did a post-test, related to how they perceived various aspects of technological systems and how the teaching could be improved. They observed that the concept of input was clearer to the pupils than output, but that the latter conception improved somewhat during the intervention. Both before and after the intervention, however, the pupils had a linear conception of systems, and they found it difficult to separate between a process and a system. Flow of matter in a system was the easiest concept to understand, while information 
was the most difficult. Setting boundaries to systems was also a challenging task. Although their systems thinking was rather limited, the pupils were at least able to reach beyond basic descriptions of technological systems (Koski and de Vries 2013).

In recent years there have been a number of Swedish studies on technological systems in relation to technology education. For example Örtnäs studied how secondary school pupils perceived technological systems in their everyday life. Her conclusion was that with a little scaffolding they could understand how technological systems such as the mobile phone network and the washing machine work; at least, they understood the structure of the systems and how they related to subsystems and humans. However, the older pupils showed a better understanding of single components than the younger ones (Örtnäs 2007). Svensson, who studied 10- and 15-year-old pupils' experience of technological systems, concluded that they understood the structure quite well but were not so knowledgeable about how components interact and how humans fit in the systems (Svensson 2011).

Klasander concluded that systems thinking among teachers is often hampered either by a focus on scientific, reductionist aspects of systems or a focus on single artefacts (Klasander 2010). Svensson and Klasander studied how two groups of technology teachers plan their teaching about technological systems in lower secondary school. The study showed that the teachers require more knowledge about the similarities and differences between various technological systems. A better understanding of the system's components and different layers could also contribute to a more developed understanding (Svensson and Klasander 2012). Schooner, Klasander and Hallström (2015) investigated Swedish teachers' views of assessment of technological systems, and found that they mainly focussed on the systems' structure, input, process, output, and consequences for the environment (Schooner, Klasander, and Hallström 2015).

Even though the previous research on technological systems in technology education is rather limited, one can draw a few conclusions of relevance for this study. ${ }^{1}$ First of all, pupils are better at understanding the structure of a system than its behaviour, and control mechanisms and the flow of information are particularly difficult to grasp. Secondly, pupils gain a deeper understanding of systems as they grow older, especially regarding the included components. Thirdly, pupils also better understand systems when they are scaffolded, either by an interviewer or by teaching interventions. Fourthly, both pupils and teachers have a fundamental conception of structure, input, process, and output of technological systems.

\section{Theoretical framework, Methodology and Research Ethics}

In order to underpin the study theoretically, a broad synthesis of established (technological) systems theories was compiled into a set of 'system significants' (e.g. Bertalanffy 1973; Bijker, Hughes, and Pinch 1987; Capra 1996; Churchman 1979; Ellul 1980; Hughes 1987; Ingelstam 1996, 2002). These system significants thus constitute what are considered the most important characteristics of technological systems according to the literature, and were accordingly clustered into groups of central concepts: the technical core of a system; hierarchies, sub-systems, components; connections and wholeness; system boundary and surrounding; isolated, closed or open systems; control, feedback, flow of information; systems' functions and behaviour, processes, models; scale and complexity; dynamics, development, change; socio-technological perspectives; and systems for innovation, conditions for production. These significants informed the construction of an in-depth, qualitative survey designed to gauge student teachers' conceptions of technological systems, but they also guided the analysis of the survey (cf. Mioduser, Venezky, and Gong 1996). After a pilot study the number of questions was reduced; the original survey was too long for students to be able to complete within a reasonable time limit (Hallström and Klasander 2013).

\footnotetext{
${ }^{1}$ In the research overview we have left out a large body of research concerned with how children and adults understand complex social and natural systems (e.g. Hmelo-Silver and Azevedo 2006; Resnick and Wilensky 1998; Booth Sweeney and Sterman 2000, 2007; Yoon 2008). Although there certainly are connections to our research - which is evident in our discussion - we focus on educational research on technological systems here.
} 
The survey was constructed to identify the student teachers' conceptions of more generic aspects of technological systems, that is, a survey question often deals with one particular system but what we are after is a more general understanding that is applicable even to other systems (cf. the significants). The survey deals with technological systems more directly; how they work and evolve, the relationship between the components and the whole, the system borders, relationship with human beings, society, the environment etc. The selection of systems considered by the survey was thus guided both by the goal to include as many generic aspects as possible, but also the desire to include as many different systems as possible, all of which should contribute to variation for the students. There were three main questions about three kinds of systems in the survey:

1. The mobile phone. The students were provided with some of the operations that a mobile phone performs and they were asked to explain if and how these operations were system dependent as well as what systems were connected to the phone. Then they were asked to describe the structure of one of these systems and how it worked together with the phone, and, finally, how the telephone operator could tell from where a certain call was made and what it cost. What we intended to get information on here was the students' conceptions of (a) dependence of components/devices on technological systems, (b) system structure and function, and (c) flow in a system.

2. The elevator. The students were both provided with, and also asked to give some information about what the elevator needs in terms of human-given and automatic input in order for it to work, for instance, buttons that are pressed but also information that is gathered by various sensors. They were also asked to describe a system that worked in a similar manner to the elevator system. Here we wanted to study students' conceptions of (a) components in a system and the role of humans, (b) components such as sensors in a control system, and (c) system structure and function.

3. The electric grid system. The students were provided with historical maps of the evolution of electricity networks in comparison with telephone networks. They were asked what similarities and differences there were. They were also asked to name components in the electricity system today and what would happen if one of these malfunctioned, that is, how it would affect the whole system. Here we wanted to find out about students' conceptions of (a, b) system structure, expansion and evolution, (c) components in a system, and (d) system structure, components, and flows. ${ }^{2}$

Because previous research indicates that scaffolding may add to or expand students' conceptions of systems, we employed certain built-in scaffolds in the survey, as described above where we provided students with bits of information in each question. This article is thereby informed by sociocultural theory in that it was the students' conceptions of technological systems in a social and cultural context that we studied (Schoultz, Säljö, and Wyndhamn 2001).

The empirical material was consequently collected by conducting qualitative, in-depth surveys with twenty-six Swedish technology student teachers. They were all participating in teacher education programs at three Swedish universities. The selection was made by making a kind of purposive sampling; sending out a number of surveys to the mentioned universities where contact persons asked students whether they wanted to participate. A number of students were asked but few agreed to participate - the response rate was ca. $30 \%$. However, our survey can be likened to a qualitative interview, where the object is to identify the qualitative conceptions of technological systems of the students that participate. The goal was thus to get as varied a selection of informants as possible, and we obtained a spectrum of informant backgrounds; both in in-service and pre-service education, and from preschool class up to upper secondary education, although the absolute majority were studying to become teachers in the Swedish compulsory school (ages 7-16). Few of the participants had studied technology or technology education before, and we tried to reach them as early in their current courses as possible so as to obtain their intuitive, everyday conceptions as far as possible. A majority of the students worked or had worked as technology teachers, which means that several of them were or had been unqualified to teach technology. The informants were all informed about the purpose of

\footnotetext{
${ }^{2}$ The complete survey instrument can be obtained from the first author.
} 
the study and that they could terminate their participation whenever they liked, as well as the fact that all information about their identities would be kept confidential and the collected material would be used for research purposes only (Robson 2002).

The survey transcripts were entered into the MAXQDA software in order to support the analysis, coding, and categorization, which were performed based on the Swedish transcript (cf. Jeppsson et al. 2013). Excerpts that have been included as particularly illustrative were translated into English by the authors. A hermeneutic method was employed when analysing the text material, that is, single texts were related to the whole body of texts and the systems context in a reciprocal, re-interpretive way (Ödman 2007; Postholm 2006). For the purpose of telling when something related to technological systems was expressed in the students' answers (reading-in), and for the analysis and interpretation of how systems-related content was expressed or if something was excluded (reading-out) (Säfström 1994, 1999), the theoretical lens of the above mentioned system significants was employed in order to analyse the students' conceptions of technological systems. Since a minor part of the empirical material was also made up of the students' drawings of components and systems, often with textual comments, we also employed so-called icono-textual analysis. This is a hermeneutic analysis of the drawings by themselves or together with textual comments (cf. Axell 2015).

The final stage of the analysis went beyond relating student propositions to the system concepts/significants, and we ended up with a new set of codes/categories to describe the students' understanding of technological systems (cf. Othman, Treagust, and Chandrasegaran 2008; DiGironimo 2011). We adhered to Cobern's (1994) view of the relationship between conceiving and understanding: ' $[\mathrm{U}]$ nderstanding is the epistemological or thinking process by which one comes to conceptual comprehension' (Cobern 1994, 586).

The validity of the study was ensured by carefully trying out the questions in several stages; first a trial with lower secondary pupils which led to revision, then a pilot with five student teachers

(Hallström and Klasander 2013) with a subsequent reduction of the questions. The analysis of the data was also peer-reviewed at a research seminar in order to ensure the validity of the categories (Larsson 2005). Our results can only be seen as representative of the 26 students, although we hope to generate more general inter-subjective understanding through them (Ödman 2007).

\section{Results}

The analysis of the empirical material resulted in a four distinct, qualitative categories. The first one is atomistic, which is made up of answers that reveal student conceptions of the parts or components in themselves. It is also possible that if one presses a button then something happens, without making the system connection or seeing flows of information, matter or energy in the system. The second category is systemic, which includes a conception of flows and connections that make the components into a system, as well as a conception of the physical extension of the system (with wires, cables, pipes etc.). Furthermore, this category includes how the components interact more precisely and how flows of energy, matter, and particularly information, contribute to the working of the system, for example, through feedback loops. The third category is holistic, which denotes the students' conception of wholeness and context as well as connections, comparisons and dependences between systems. It can also be connections between the system and the surroundings, for example, the physical surroundings/environment or issues of sustainability. The fourth one is the undefined category, which consists of student answers that were either left blank or were in some way or another insufficient or undefined in relation to the assignment.

\section{Atomistic}

Our first example was a modern mobile phone that performs a number of different operations, which are more or less dependent on several external technological systems, for example, tele and radio communications systems and GPS. Although a number of such operations are mentioned in the survey - pre-printed with boxes to tick - the students still found this part difficult. Some respondents wrote that the mobile phone is connected to technological systems, but suggested single artefacts or operators as connections outside of the phone itself. For example, one respondent proposed that telephoning, surfing, radio and GPS require external systems but merely wrote that GPS needs a 
satellite. Another student wrote that telephoning and surfing are dependent on 'telecommunications operators such as Telia [Swedish operator]', but did not link this to any particular system. We thus consider these as atomistic conceptions of the phone's external connections, since they involve another device, component or operator, but not a system.

Mostly, however, the students looked inward when asked about what systems these operations rely on, that is, they associated a technological system with either the telephone itself or its software, such as the operating system or specific programs. Several students, for instance, pinpointed 'software' as the system enabling all the specified operations, except for telephoning, surfing, and GPS which require 'some kind of subscription' or 'telecommunications operator'. Another student claimed that the calendar and the address book demand a connection to iCloud, but did not specify what iCloud is or what external technological system makes it sync with the phone.

The students were also supposed to describe the structure and function of one of the systems connected to the mobile phone. Here a smaller part of the student answers were considered atomistic because they looked inward to the software system(s) inside the phone, mostly the operating system. One person thus wrote: 'The operating system is, like the spider in the web, the part of the phone that connects together all the functions of the phone and tells the phone what to do.' The quote implies that the operating system is not a technological system that the phone connects to externally in order to work, but rather the software 'junction' inside that makes the phone work. Another student wrote a more explicit explanation of how the operating system initiates itself:

The mobile starts up => POST, the telephone checks the hardware. Forward to start-up files => Android starts up $=>$ You enter your PIN code. You are inside Android.

Furthermore, the students were asked how the mobile phone operator can keep track of where the users are calling from as well as how much they should pay, which generated many answers which were labelled atomistic. Most of these students could roughly tell how the tracking and payment work, for example, the importance of the SIM card as an identifier for paying the right fee. Many of them connected the tracking to 'registration via computer programs' or 'checking', but did not say anything about surrounding artefacts or systems, or communication or flows of information. A typical quote is: 'Positioning of telephone. Registering of calling time which is connected to the fee to pay. Deciding where receiving phone is.' Some students mentioned GPS, satellites or the distance from the phone to base stations, but there was little information on how the positioning and payment really work as a function of the connection and flows between one or several components and systems. In sum, quite a large number of the investigated students showed atomistic conceptions of how a mobile phone operates, and many of these thought of a system as software not an external system.

The students were also asked about the elevator as a control system. They were asked to fill in what they would do in an elevator and what kind of information this particular action (entering, pressing buttons, etc.) would give to the system. This part is in itself atomistic in the sense that the students could only provide information about different buttons and sensors in the system, how they work and how human actors can manipulate them. There were some very brief answers where they only wrote one or two things that happen when riding an elevator, and there were also some very elaborate answers, depending on how many different things they wanted to fill in. Most of the students mentioned basic operations: pressing the button to make the elevator come to one's floor, or, once inside the elevator, pressing the open/close button or the button for the desired floor, etc. The part causing most confusion was the second item, already partly filled in, about what one should do to get access or permission to ride. Answers that were given included using an access code, key or card, but there were also less obvious answers such as pressing the button or just being in the elevator. The emergency or alarm button was also open to many interpretations: calling for help, calling the police, fire department, or just 'staff'. A few also equated this button with stopping the elevator: 'Press emergency - The elevator must stop; Press [button with] telephone receiver - Want help'. Either way, several students separated the stop function and alarm/emergency function of the elevator system, even though they were described in different ways. 
The students were also asked to fill in what information they thought the elevator system would need to gather automatically via sensors, as well as how this was done, in order for it to operate correctly and safely. This required a conception of control systems and how sensors work. A majority expressed atomistic conceptions, that is, they mentioned sensors but left it at that and did not mention anything about their connection or signals to the elevator control unit. These students were very familiar with an elevator and how it works, and thus they expressed a basic conception of sensors in that they could roughly tell what kind of information a certain sensor gathers. They expressed, for instance, a notion that the sensors in the elevator door can somehow sense when a person is blocking the entrance so that it will not close, or that a sensor measures the total weight of the elevator cage in order to prevent overloading.

However, when it came to identifying each sensor and how it works, the results varied. Regarding identification of the sensors in the elevator door, for instance, there was a fairly large variance between the students' answers. Some responded with 'sensor in the doorway' or 'a sensor that senses that nothing is between the doors', while others said that 'a light beam is broken' (or similar), and yet others wrote about sensing pressure. The last group was the largest one, which may reflect how most elevator doors work. Yet there was a range of different answers given here, for example:

Sensor that detects a spring load.

The doors open when they meet resistance.

A pressure sensor.

The part of the survey that had the most variety of answers was that about controlling the braking of the cage before the 'right' floor, which is interesting because there are several components that need to interact in order for the braking to work. However, the answers were largely atomistic and the function of slowing down before a floor was attributed to a number of different sensors or other technical solutions such as a 'distance sensor', 'sensor at each floor', a 'time sensor/keeper', and even the length of the elevator cable, although it was not explained how the cable might be used for this. Some students elaborated their answers a little more:

'Countdown' of the number of floors.

A sensor that detects which floor the elevator is on.

Sensor that is placed where the elevator should slow down.

Many of these students obviously seemed to agree that there must be a sensor somewhere that keeps track of where the elevator is and/or where it should stop, but exactly how this works remained unclear to the majority. So even though the conceptions of how sensors work are labelled as atomistic, the degree of actual device knowledge is considered low (Mioduser, Venezky, and Gong 1996).

The students were further asked to describe a technological system that works in a similar way to the elevator system. Some students could mention a few parts of similar systems, although systemic aspects such as flows were really left out, as seen in these three examples:

Green lights at intersections, sensors in the roadway near oncoming vehicles.

Coffee machine, you can choose what you want by pressing the buttons, then the order is processed automatically.

Conveyor belt in a factory on which the goods are transported, processed, and packaged.

There were also students who provided answers verging on more systemic conceptions. One implied flows and connections between components in an automatic vending machine, and another was more explicit about sensors and control when describing automatic doors. However, the flows and connections were still only implied and it was not clear how the automatic doors and sensors work as a system: 
Sensors notice that I approach, and the doors open. When I have passed, the doors close automatically.

There was also a description of a washing machine as a control system, although here, again, the flows and connections were suggested rather than explicit. It was therefore atomistic; no concrete sensors, flows, connections, or feedback loops were mentioned:

How you can control it yourself:

Close the lid - safe to start; turn on the machine - something will happen; adjust the program the machine knows in what order it will do things.

How the system automatically controls/steers itself:

Time to fill up with water; enough water; drain water; spin - is it evenly distributed in the cylinder, otherwise turn off!; revolve the cylinder - wash.

In the third and last example the students were shown historical maps of the extension of the telephone network and the electric grid in Sweden, for the former between 1887 and 1895, and the latter between 1900 and 1961. They were asked to say what similarities and differences between these two networks they could see as regards their expansion. No answers were labelled as atomistic, however, as the questions were explicitly about the extension of networks and, thereby, the flows of the system, and the students' answers reflected this.

However, the students were also asked to describe components of the electric grid system today. All students filled in the form, and since it was construed as a task where the students were to fill in information about components in the electricity system, almost all answers were labelled as atomistic. Some mentioned power plants or power sources - nuclear, water, wind, or sun power - as components of this system, but some also mentioned artefacts such as transformers/transformer stations, industries or cables. They thus focused almost entirely on power plants or sources as principal components of electricity distribution systems (cf. Gyberg 2003). Some students expressed conceptions of other important components of the electricity system, for example, isolators, gauging apparatuses, electrical cabinets, turbines, high tension lines, but also other components or secondary systems such as roads and railroads. They also mentioned other power sources such as wave energy, natural gas, and biomass fuel, although this was rare. One person also mentioned a human actor in the system, namely a mender.

Finally, the students were asked to describe how it would affect the whole electricity system if one component failed. Many students provided answers which were designated as atomistic, since they focused on components in themselves or did not explain how components and flows influence or relate to the system as a whole. Examples include:

Electricity pylon falls => power line breaks.

Transformer station is on fire close to a smaller town, cuts off electricity until it is mended. No alternatives available.

Electric power station - no production, nothing to transport. No electricity in the house and heat will disappear unless you have another way of heating than that which requires electric power.

There was also one student who managed to incorporate an environmental perspective, despite the fact that there was no attempt at explaining how the failure of the component affects the system:

A nightmare scenario is that a nuclear power plant goes to 'pot'. Certainly, we would lose a lot of power but what is worse is the disaster that may become a reality for a very long time ahead, and now we're talking ENVIRONMENTAL DESTRUCTION on a large scale where acidification [...] seems like a drop in the ocean.

\section{Systemic}


As regards the mobile phone, some of the respondents expressed some kind of systemic conception. That is, apart from the fact that they saw the mobile phone as a component in itself, they were also of the view that it was dependent on some external system(s). Even though one student saw certain functions in the phone as only connected to the local 'WLAN', most of these students expressed a more developed conception including flows of information (for example, sync, update, multiplayer mode) and one or more external technological systems. This more elaborate view was therefore typical of this group of students, and several of them could pinpoint some principal systems connecting to the mobile phone to make it work, such as telecommunications systems (3G/Internet), radio communications and GPS (via $3 \mathrm{G}$ or satellites). The Internet was associated with a multitude of operations such as surfing, Internet games, calendar sync, music streaming, etc. Many student answers specified the Internet as the system enabling even telephone, radio, camera, and clock functions on their mobile phones. However, today many mobile phones actually use the Internet to perform these operations and there is also probably a trend towards increased Internet dependence through IP telephoning, Internet radio, uploading of pictures, syncing of clock functions, etc.

Many students were successful in describing system characteristics such as flow of information or energy. They described these with words such as 'communication', 'signals' and 'radio waves'. One student described the sync function and how it relates to an external system (the Internet) in the following way:

ICloud is a 'cloud system', that is, a system which saves the information on a server connected to the web. This makes it possible for the saved information to be synced to other units accessed by the same user. The calendar and the notes can function without iCloud but then I do not have access to the calendar posts I have entered on other units.

Quite a few in this group chose to draw pictures of one or two of the connected systems, notably parts of telecommunications and mobile broadband systems. Some of these were quite elaborate with several different components such as mobile phones, landlines, base stations, and satellites, with a flow of information in between, both wireless and by landline. One student also included a telephone station with calling exchange. A few students described the global positioning system (GPS), but restricted their drawings to include a mobile phone and a satellite and the flow of information between these two.

Several students also gave detailed descriptions of how the operator can determine the position of the phone and how much should be charged for phone calls. The conceptions of how the operator determines payment were rather limited and fragmented, however, despite the more systemic outlook. What mainly separated these students from the larger group of students who provided atomistic answers, therefore, was the fact that this group could pinpoint flows of information and two or more components that interact in order for the tracking to work. Keywords such as 'communication', 'connection', 'transmission' and 'signal' are proof of this, but also the descriptions of the interacting components. A quite elaborate example is presented below:

The mobile phone needs to have contact with mobile towers and the more towers that are in contact with the mobile phone, the more precise the location of the mobile phone will be as the towers just overlap their coverage in few areas. What I pay depends on how long I talk, which computer systems linked to the masts keep an eye on.

Another example shows a quite advanced conception of the systems involved, although the payment part is less elaborately described and mobile phones do not use IP addresses in this way:

They see the phone's IP address and see what mobile tower/base station one is communicating through. Your subscription/account is associated with your SIM card, which is linked to the IP address.

Furthermore, there were a few students who incorporated something about the flow of information in the elevator system, although it was not elaborated on very much. These students mentioned a 'signal system' or that a 'sensor in the door sends a signal if someone is nearby'. One student articulated this 
in more depth: 'There is a sensor on the door which senses pressure and sends a signal to the elevator system.'

There was one student who provided a description of another similar control system that can be considered as systemic, that is, where you can see connections and flows between components as well as an implied feedback loop. This student's example is that of automotive cruise control as a control system:

Cruise control of the car, for example, you determine the speed (today without a throttle cable) using a potentiometer which can be coupled with a servo motor which is connected to the speedometer. If the measured value does not correspond to the given value, the system is out of service. Measured values are often some resistance or impulses per unit of time.

Many students provided systemic answers of various kinds regarding similarities and differences between the historical evolution of the electricity and telephone systems, although these answers varied in terms of how elaborate they were and what they focused on. As regards the similarities between the two systems, many students described how the networks evolved from being smaller and rather limited to more widespread, as the following examples show:

From small separate parts to a (coherent) system.

Both are expanded sporadically with local/regional efforts. After a while, primarily big cities and the Norrland coast are connected together.

Start to be built in 'colonies', later on built together. Begin in larger cities/'important' places. Start in the south, later on extended northwards.

The last aspect - the extension from south to north, and thereby from more to less densely populated regions of the country - was something that was pointed out by several students. This was expressed, for example, like this:

It started in southern Sweden and spread northward. It began in smaller systems which were later connected into bigger ones.

[. . .] Densely populated areas were extended first; less populated ones later on. First shorter communications, then longer [telephone].

The students were also asked to look for differences between the systems and then also to venture possible explanations as to why such differences occurred, which is probably why the replies were very varied. We provide a few examples of this type of reply, but they nonetheless cover a wide spectrum of answers:

More rapid extension of telephone lines.

The telephone network was several smaller sub-systems whereas the electric grid was soon made up of a few larger junctions.

The telephone was connected from the start. The electric grid began in several places disconnected from each other.

A few students were able to make some kind of connection between the extension of the systems and the historical context, mostly to explain the expansion northward and from densely to less densely populated areas, although this was of course not the purpose of this survey question. ${ }^{3}$ Historical change was hinted at by writing 'after 1940' or 'after a while', and one or two wrote about 'need' and thereby implied a cause or driving force behind the extension of the networks (cf. Hallström and Gyberg 2011).

\footnotetext{
${ }^{3}$ The maps are from different time periods but were picked out only for the purpose of seeing what the students could say about similarities and differences between the geographical distributions of the two systems.
} 
A few students came up with answers regarding component failures in the electricity system that have been categorized as systemic. These students could indicate flows and how the failure of one component influences parts of the system. Here are two examples of this:

If transformer stations failed, remote parts of the country would be without electricity and yet other parts would risk being over-charged and collapsing.

If a tree falls on a power line, the line will break. The current has no other way to go. $\rightarrow$ No power.

Compared to the student answers labelled as atomistic, some of the systemic ones were considerably more developed in the sense that they showed that components are dependent on one another, or can replace each other, and that there are crucial flows that can be manipulated in various ways:

If one electric power station breaks down, maybe another one can complement its production.[. . .]

The energy source (e.g. a hydroelectric plant) was eliminated and electricity cannot be delivered. Other energy sources may need to be brought in, and, if necessary, reserves will be used. If necessary, electricity may need to be imported from other countries. In a longer crisis, the tariff will probably be raised and people encouraged to conserve electricity. If most energy sources disappear it may be necessary to ration electricity or find alternative sources.

This last quote also shows how a failure in one part of a system can spread and be reproduced throughout the system at different levels, and even influence people, the economy, and the environment.

\section{Holistic}

In comparing historical electricity and telephone systems a few students expressed what can be labelled as more holistic conceptions of systems, that is, they were able to see the systems as a whole as well as their context(s), and they could make more consistent comparisons between systems:

\footnotetext{
The telephone network was more evenly expanded in the second picture. The electric grid was extended with high tension lines to be able to transport energy from hydroelectric plants in the north to the south where most users live.

The electric grid was extended with large main lines which could later be split up between users in many places, whereas the telephone network became an interconnected, compact [finmaskigt] network in order to, little by little, cover the lion's share of the inhabited areas.
}

The students with the more holistic conceptions were thus able to pinpoint typical characteristics of these systems by making more informed geographical comparisons, for instance, the fact that the expansion of the electric grid was based on long, large power lines for the distribution of electricity from north to south, in contrast to the telephone wires which initially connected local users and later spread between cities and regions (Kaijser 1994).

\section{Undefined}

On average, around half of the respondents filled in the survey questions by either leaving them blank or providing insufficient answers, hence the category 'undefined', although the category contains a good deal of variation between systems and what aspects are focussed upon. For example, as regards the mobile phone, one student wrote that 'all of [the mobile phone's operations] are included in some kind of technological system to be able to work,' but did not mention such a system. These students thus claimed that a mobile phone is dependent on one or more technological systems, but they could not leave the level of the single phone and relate it to specific systems. In another example, when 
asked to compare the elevator to another technological system, many students either left the question blank or just wrote the name of such a system without trying to describe it, for example, 'car', 'assembly robots in industry', or 'computers and their systems'. It is conceivable that they understood 'describe' to mean 'mention', and therefore just named some such system, but they still showed no conception of a system.

When asked about seeing possible similarities between the electricity and telephone systems there were also students who revealed a historical 'misconception'. In these answers it is assumed that one similarity between the electric grid and the telephone network is that they were initiated and extended in urban or densely populated areas first, something which these quotes exemplify:

Great concentration around big cities.

The expansion is pretty similar and also shows where it is most densely populated.

That it was expanded more in large cities and was spread to the countryside.

While this is largely true of the telephone network, it is a very simplified explanation to the evolution of the electric grid. Electricity networks were initially established mainly in the countryside in close proximity to water resources and industrial establishments. The introduction of the electric grid in Sweden thus largely coincided with industrialization, and industrialization began to a greater degree in the countryside than in the cities (Kaijser 1994; Jakobsson 1996).

\section{Summary of Results}

Many students acknowledged the mobile phone's system dependence, but often without any kind of explanation of how or why. Those who could look beyond the single artefact claimed that the phone seems to be connected to either another artefact or an operator company. Mostly, however, they saw the internal software in the form of the operating system - 'the spider in the web' - as the most important system that makes the phone work. We use the label atomistic to refer to this way of seeing various devices and components as largely solitary and with few, if any, connections to other components. The students in this category have a basic understanding in the sense that they know how a mobile phone operates, what it does, but when it comes to explaining how various operations are carried out and how they connect to other external (or internal) systems, they are at a loss.

A similar group of students did express a more systemic view of the mobile phone, in which various flows of information and energy were pinpointed and they could also distinguish some important technological systems connecting to the phone: $3 \mathrm{G}$ telephone and broadband, radio, and GPS (satellites/3G). Some students did not separate these completely, which was probably due to the fact that they are becoming more and more merged into a single $3 \mathrm{G} / 4 \mathrm{G}$ broadband system. However, even these students could not express with any elaboration how the various components operate.

The elevator was a very familiar system to the students. Many student answers were atomistic with one or two exceptions, because they could, for instance, describe many common operations such as pressing a button to make the elevator go to the desired floor. The students were also proficient at naming various buttons, sensors and operations, but they did not show much understanding of how they work, or how the flows in the system make the components work together. They described, for example, an operation such as the closing/opening of automatic doors, although they did not show how the flows of information went (e.g. between sensor and operating unit) and there were various views of how the sensors work. When asked to compare the elevator with similar systems almost all students left the response blank. One or two provided an answer such as when you press the button on a coffee machine this makes it serve automatically, but without any notion of what flows of information make this happen.

The electric and phone systems differ slightly from the other two examples in that the students were asked to provide information of components separately, and flows, connections, and geographical extension of the systems separately. This means that in the first case all answers were either undefined 
or atomistic, for the students were very proficient at naming various components and power sources such as water, wind, nuclear and sun power. One might argue that these are actually flows in various other systems, but in the electric grid these are transformed into electric power as symbolized by other components such as turbines and transformer stations that the students mentioned.

As regards the geographical expansion there were roughly equal numbers of blank or undefined answers as systemic ones, and a couple of holistic answers. The thing that the students with systemic conceptions noticed most clearly was the fact that the networks grew from being smaller and rather limited to more widespread, and that they expanded from more to less densely populated areas of Sweden (even though the latter was not strictly true of the electric grid). Those who provided holistic answers could also provide a description of a whole system as well as making informed comparisons between the two systems, based on the maps given in the survey.

When asked what would happen if a component in the electricity system failed and how it would affect the whole system, a majority of answers were either undefined or atomistic. In the latter case, the students mentioned various failing components such as pylons, power lines and transformer stations and wrote that this would affect other parts of the system, but did not describe how it would affect the system in terms of disconnected or re-directed flows of electricity or information. A few systemic answers indicated flows - for example 'current', 'electricity' - and how the failure of one component influences at least parts of the system. The issue of dependency between components, systems and humans/environment was also more obvious among these student answers.

\section{Concluding Discussion}

In conclusion, atomistic conceptions of technological systems dominated the student answers of this study. Most students could see the various parts but were unable to connect them to a wider context particularly flows of information but also matter and energy in a system as well as connections to other systems and the societal context. A smaller proportion of the students could be labelled as systemic because they could conceive of some flows in the systems. Very few students were categorized as holistic, that is, those with conceptions of wholeness of a system and the ability to compare systems with each other. However, what all three groups of students had in common was a low degree of what Mioduser et al. (1996) call device knowledge; they knew rather well what components, devices, and systems $d o$, but to a much lesser degree how they work and why.

The parts of the systems that the students did understand, therefore, were mostly the visible parts, either components, devices, or products, such as buttons, hydroelectric plants, power lines or the interface with the software inside the mobile phone - at least they understood on a superficial level. This study consequently confirms the results of Klasander (2010) who concluded that system understanding among teachers is hampered by an exaggerated focus on artefacts and components. Svensson claimed that understanding the artefacts in a system can be a good starting point for understanding the whole system (Svensson 2011), and we can see some such understanding in that the students could name some components and relate them to each other. Regarding the mobile phone there were more elaborate student conceptions of dependence on secondary systems (Hughes 1987; Summerton 1998) than the other two systems that we investigated. However, most of the time artefacts tended to obscure relations between the components and the whole system. It is as though it was too complicated to focus on artefacts and system at the same time. This is not surprising because Kroes et al. (2006) talk of a 'Russian doll effect' when analysing a technological system, where each component can also be viewed as a sub-system, depending on your perspective (Kroes et al. 2006).

The more 'invisible' or abstract aspects of the systems such as flows of information, energy or matter, or the control operations performed by the control unit in the elevator system, were difficult for a majority of the students. The flows of information in a system were particularly complicated to understand. The students could identify the input and often the output of the systems (Koski and de Vries 2013), that is, what systems or components $d o$, but the processes that take place within the systems remained elusive (Mioduser, Venezky, and Gong 1996). One interesting finding here is that the conception of the extension of electricity and telephone infrastructure was quite elaborate for 
many students, but this infrastructure can still be regarded as a more visible part of these systems (though it still hides the flows, thereby making them more 'invisible'). It was yet overall a challenging task for the students to compare between systems.

The role of humans was largely missing in most students' answers. Humans were considered important to the systems but mostly as users. The students did not see humans as actors on a more systemic level, for example, what Hughes (1987) calls system builders: system owners, innovators, politicians, etc. (Hughes 1987). One can say that defining the role of humans was more difficult for students the more complex the system, which also goes for the understanding of components in relation to systems. In the more complex socio-technical systems such as mobile phone, electricity, and telephone systems with a great many 'hidden' flows and societal components, the various roles of human actors were difficult to understand for the students.

This study confirms previous research in that the students had a basic understanding of structure, input and output of a technological system. However, the built-in scaffolding of the survey did not really help the students to gain a better understanding of systems. The adult students of this study thus did not seem to have better systems understanding than school pupils and teachers in previous studies, although this is also in line with previous investigations of the general system thinking capabilities of children and adults such as Booth Sweeney and Sterman (2000, 2007).

The technology student teachers in this study apparently had a difficult time understanding the technological systems presented in the survey. They also answered the questions unevenly, that is, one student could perform well in one part of the survey but leave another part blank. Consequently, we propose as a future study a new analysis of how each and every student performed in the individual parts of the survey, which would be an opportunity to study system conceptions on an individual level.

\section{Pedagogical implications}

The most important implication of this study is that students need to be trained in systems thinking (cf. Booth Sweeney and Sterman 2007). This is not something that comes naturally but requires a carefully constructed curriculum and well-educated teacher educators. Such a curriculum should include systems components that the student teachers of this study seem to lack a sufficient understanding of: how components work and connect to each other, flows (especially of information), system dependency, and the human role in technological systems. However, even the more softwareoriented approach to technological systems developed in computing and information systems research (e.g. Burton-Jones and Meso 2006) needs to be included, because some kind of software system is included in most new technologies.

Finally, as we have pointed out, the three categories of conceptual understanding in this study atomistic, systemic, and holistic - are not normative but are distinct qualitative categories by which we have coded and carried out the final stage of the analysis of our empirical data. These three categories cover the range of understandings of technological systems found in our data. We are of the opinion that all these conceptions are needed in order to obtain an in-depth understanding of technological systems. It is not enough to use one or the other; there is an overlap of the three conceptions that we think is something to highlight in teaching about technological systems.

\section{Acknowledgements}

The authors wish to thank Annelie Bodén and Per Norström for helping out with the distribution of the surveys. Thanks also to the TESER working seminar participants for providing valuable comments on an earlier version of the manuscript.

\section{References}

Axell, C. (2015). Barnlitteraturens tekniklandskap. En didaktisk vandring från Nils Holgersson till Pettson och Findus. Norrköping: Linköpings universitet. Ph.D. Thesis. 
Bertalanffy, L. von. (1973). General system theory: foundations, development, applications. Rev. ed, The international library of systems theory and philosophy. New York: Braziller.

Bijker, W.E., T.P. Hughes, and T.J. Pinch. (1987). The Social construction of technological systems: new directions in the sociology and history of technology. Cambridge, Mass.: MIT Press.

Booth Sweeney, L., and J.D. Sterman. (2000). Bathtub dynamics: initial results of a systems thinking inventory. System Dynamics Review, 16(4), 249-286.

Booth Sweeney, L., and J.D. Sterman. (2007). Thinking about systems: student and teacher conceptions of natural and social systems. System Dynamics Review, 23(2/3), 285-312.

Burton-Jones, A., and P.N. Meso. (2006). Conceptualizing Systems for Understanding: An Empirical Test of Decomposition Principles in Object-Oriented Analysis. Information Systems Research, 17(1), 38-60.

Capra, F. (1996). The web of life: a new scientific understanding of living systems. 1st Anchor Books ed. New York: Anchor Books.

Churchman, C.W. (1979). The systems approach. Rev. and updated. ed. New York, N.Y.: Dell Pub. Co.

Cobern, W.W. (1994). Point: Belief, Understanding, and the Teaching of Evolution. Journal of Research in Science Teaching, 31(5), 583-590.

Compton, V., and B. France. (2007). Redefining Technological Literacy in New Zealand: From concepts to curriculum constructs. Pupils' Attitudes Towards Technology 18, Glasgow, 200705-14.

DiGironimo, N. (2011). What is Technology? Investigating Student Conceptions about the Nature of Technology. International Journal of Science Education, 33(10),1337-1352.

Ellul, J. (1980). The technological system. New York: Continuum.

Frank, M. (2006). A Systems Approach for Developing Technological Literacy. Journal of Technology Education, 17(1), 19-34.

Ginns, I.S., S.J. Norton, and C. J. McRobbie. (2005). Adding Value to the Teaching and Learning of Design and Technology. International Journal of Technology and Design Education, 15(1), 47-60.

Gyberg, P. (2003). Energi som kunskapsområde. Om praktik och diskurser i skolan. Linköping: Linköping University.

Hallström, J., and P. Gyberg. (2011). Technology in the rear-view mirror: How to better incorporate the history of technology into technology education. International Journal of Technology and Design Education, 21(1), 3-17.

Hallström, J., and C. Klasander. (2013). Technology Education for Systems Thinking and Sustainability: What Swedish Pre-Service Technology Teacher Students Know About Technological Systems. In PATT 27 Technology Education for the Future: A Play on Sustainability: Christchurch New Zealand 2-6 December 2013, edited by P.J. Williams and D. Gedera. Hamilton, New Zealand University of Waikato.

Hamlin, C. (1992). Edwin Chadwick and the Engineers, 1842-1854: Systems and Antisystems in the Pipe-and-Brick Sewers War. Technology \& Culture, 33(4), 680-709.

Hmelo-Silver, C.E., and R. Azevedo. (2006). Understanding complex systems: Some core challenges. The Journal of the Learning Sciences, 15(1), 53-61.

Hughes, T.P. (1983). Networks of power: electrification in Western society, 1880-1930. Baltimore: Johns Hopkins Univ. Press.

Hughes, T.P. (1987). The Evolution of Large Technological Systems. In The Social Construction of Technological Systems, edited by W.E. Bijker, T.P. Hughes and T.J. Pinch, 51-82. Cambridge MA: The MIT Press.

Hughes, T.P. (2004). Human-built world: how to think about technology and culture. Chicago: University of Chicago Press.

Ingelstam, L. (1996). Complex technical systems. Stockholm: Forskningsrådsnämnden (FRN). Ingelstam, L. (2002). System - att tänka över samhälle och teknik. Stockholm: Energimyndigheten. Jakobsson, E. (1996). Industrialisering av älvar. Studier kring svensk vattenkraftutbyggnad 19001918., Avhandlingar från Historiska institutionen i Göteborg, nr 13. Göteborg: Historiska institutionen, Göteborgs universitet. 
Jeppsson, F., J. Haglund, T. Amin, and H. Strömdahl. (2013). Exploring the Use of Conceptual Metaphors in Solving Problems on Entropy. The Journal of the Learning Sciences, 22(1), 70120.

Jones, A. (2003). The Development of a National Curriculum in Technology for New Zealand. International Journal of Technology and Design Education, 13:83-99.

Kaijser, A. (1994). I fädrens spår. Den svenska infrastrukturens historiska utveckling och framtida utmaningar. Stockholm: Carlssons.

Klasander, C. (2010). Talet om tekniska system. Förväntningar, traditioner och skolverkligheter. Norrköping: Linköpings universitet. Ph.D. Thesis.

Koski, M.-I., and M.J. de Vries. (2013). An exploratory study on how primary pupils approach systems. International Journal of Technology and Design Education, 23(4), 835-848.

Kroes, P., M. Franssen, I. van de Poel, and M. Ottens. (2006). Treating Socio-technical Systems as Engineering Systems: Some Conceptual Problems. Systems Research and Behavioral Science, 23:803-814.

Larsson, S. (2005). Om kvalitet i kvalitativa studier. Nordisk Pedagogik, 25(1), 16-35.

Läroplan för grundskolan, Lgr 80, Allmän del. (1980). Stockholm: Skolöverstyrelsen.

Läroplan för grundskolan, förskoleklassen och fritidshemmet 2011. (2011). Stockholm: Skolverket.

Mc Glashan, A.A., and A.W.J. Wells. (2013). The road less travelled: a pre-service approach towards the technology teaching profession. International Journal of Technology and Design Education, 23:939-952.

Mioduser, D., R.L. Venezky, and B. Gong. (1996). Students' Perceptions and Designs of Simple Control Systems. Computers in Human Behavior, 12(3), 363-388.

Othman, J., D.F. Treagust, and A.L. Chandrasegaran. (2008). An Investigation into the Relationship between Students' Conceptions of the Particulate Nature of Matter and their Understanding of Chemical Bonding. International Journal of Science Education, 30(11), 1531-1550.

Postholm, M.-B. (2006). Assessment during project work. Teaching and Teacher Education, 22:150163.

Resnick, M., and U. Wilensky. (1998). Diving into complexity: Developing probabilistic decentralized thinking through role-playing activities. The Journal of the Learning Sciences, $7(2), 153-172$.

Robson, C. (2002). Real World Research: A Resource for Social Scientists and PractitionerResearchers. 2nd ed. Oxford: Blackwell.

Rossouw, A., M. Hacker, and M.J. de Vries. (2011). Concepts and contexts in engineering and technology education: an international and interdisciplinary Delphi study. International Journal of Technology and Design Education, 21:409-424.

Schooner, P., C. Klasander, and J. Hallström. (2015). Swedish Teachers' Views of Assessing Technological Systems in Compulsory School. In PATT 29 Plurality and Complementarity of Approaches in Design \& Technology Education, Marseille, France, April 2015, edited by M. Chatoney. Marseille: Presses Universitaires de Provence.

Schoultz, J., R. Säljö, and J. Wyndhamn. (2001). Heavenly Talk: Discourse, Artifacts, and Children's Understanding of Elementary Astronomy. Human Development, 44:103-118.

Standards for Technological Literacy: Content for the Study of Technology. (2000). Reston, VA: International Technology Education Association.

Summerton, J. (1998). Stora tekniska system - en introduktion till forskningsfältet. In Den konstruerade världen: tekniska system i historiskt perspektiv, edited by A. Kaijser and P. Blomkvist, 19-43. Eslöv: B. Östlings bokförl. Symposion.

Svensson, M. (2011). Att urskilja tekniska system. Didaktiska dimensioner i grundskolan. Norrköping: Linköpings universitet. Ph.D. Thesis.

Svensson, M., and C. Klasander. (2012). Teacher's professional growth in planning and teaching technological systems. Technology Education Research Conference, Surfers Paradise, Australia.

Swedish Technology Curriculum, Lpo 94. (2000). Accessed from www.skolverket.se 2013-05-17.

Säfström, C.A. (1994). Makt och mening: förutsättningar för en innehållsfokuserad pedagogisk forskning, Uppsala studies in education, 53. Uppsala: Almqvist \& Wiksell International. 
Säfström, C.A. (1999). Att förskjuta perspektiv: Läsning som omvänd hermeneutik. In Textanalys. Introduktion till syftesrelaterad kritik, edited by L. Östman and C.A. Säfström, 237-244. Lund: Studentlitteratur.

Technology in the New Zealand Curriculum. (2007). Accessed from nzcurriculum.tki.org.nz 2013-0620.

Williams, P.J. (2000). Design: The Only Methodology of Technology. Journal of Technology Education, 11(2), 48-60.

Yoon, S.A. (2008). An Evolutionary Approach to Harnessing Complex Systems Thinking in the Science and Technology Classroom. International Journal of Science Education, 30(1), 1-32.

Zuga, K.F. (1994). Implementing technology education: A review and synthesis of the literature, ERIC Clearinghouse on Adult, Career and Vocational Education. Columbus, Ohio.

Zuga, K.F. (2004). Improving Technology Education Research on Cognition. International Journal of Technology and Design Education, 14(1), 79-87.

Ödman, P.-J. (2007). Tolkning, förståelse, vetande. Hermeneutik i teori och praktik. Stockholm: Norstedts.

Örtnäs, A. (2007). Elevers vardagsuppfattningar om tekniska system. Linköping: Linköping University. Bachelor's thesis. 